\title{
PEMODELAN JUMLAH KEMATIAN BAYI DI PROVINSI MALUKU TAHUN 2010 DENGAN MENGGUNAKAN REGRESI POISSON
}

\author{
SALMON N. AULELE \\ Staf Jurusan Matematika, FMIPA, Unpatti \\ Jl. Ir. M. Putuhena, Kampus Unpatti, Poka-Ambon \\ e-mail: salmon.aulele@yahoo.com
}

\begin{abstract}
Infant mortality is an experienced child death before the age of one year. Regression analysis is a statistical analysis that aims to model the relationship between response variables $(Y)$ with predictor variables $(X)$. If the Poisson distributed response variables $(Y)$, the regression model used was Poisson regression. The purpose of this research is to get a Poisson regression model according to the significant factors that influence the infant mortality. The results shows that the significant factors are influence the infant mortality as the presentation of non medical childbirth $\left(X_{1}\right)$ and quantity of medical facility $\left(X_{7}\right)$. The case studies are infant mortality in Provinsi Maluku in 2010
\end{abstract}

\section{Keywords: Infant Mortality, Poisson Distributed, Poisson Regression Model, Regression Analysis.}

\section{PENDAHULUAN}

Angka kematian bayi adalah salah satu indikator penting dalam menentukan tingkat kesehatan masyarakat. Keberhasilan pembangunan di suatu wilayah juga dapat dilihat dari angka kematian bayi dan angka harapan hidup.

Negara Indonesia masih harus berjuang keras untuk memperbaiki indikator pembangunan kesehatan, khususnya angka kematian bayi, karena tren angka kematian bayi selama beberapa tahun terakhir belum menurun. Untuk itu pemerintah harus berupaya keras melalui berbagai program untuk menekan angka kematian bayi. Penelitian tentang angka kematian bayi pernah dilakukan oleh beberapa pihak sebelumnya. Winarno (2009) menyimpulkan bahwa persentase penolong persalinan oleh tenaga non medis dan rata-rata lama pemberian ASI eksklusif mempengaruhi angka kematian bayi. Aulele (2010) menyatakan bahwa persentase persalinan yang dilakukan dengan bantuan tenaga non medis, rata-rata usia perkawinan pertama wanita, rata-rata pemberian ASI ekslusif, rata-rata jumlah pengeluaran rumah tangga perkapita sebulan, persentase penduduk miskin, jumlah tenaga kesehatan dan jumlah sarana kesehatan mempengaruhi angka kematian bayi.
Analisis regresi merupakan analisis statistika yang bertujuan untuk memodelkan hubungan antara variabel respon $(Y)$ dengan variabel prediktor $(X)$. Bila dalam analisisnya hanya melibatkan sebuah variabel prediktor, maka regresi yang digunakan adalah Regresi Linier Sederhana. Sedangkan bila dalam analisisnya melibatkan dua atau lebih variabel prediktor, maka regresi yang digunakan adalah Regresi Linier Berganda. Apabila variabel respon $(Y)$ berdistribusi Poisson, maka model regresi yang digunakan adalah regresi Poisson. Regresi Poisson didapatkan dari distribusi Poisson, yaitu suatu distribusi untuk peristiwa yang probabilitas kejadiannya kecil, dimana kejadiannya tergantung pada interval waktu tertentu atau di suatu daerah tertentu dengan hasil pengamatan berupa variabel diskrit dan antar variabel saling independen.

Kematian bayi di Provinsi Maluku masih tergolong tinggi, untuk itu dalam penelitian ini, peneliti ingin melihat faktor-faktor apa yang mempengaruhi kematian bayi di Provinsi Maluku sehingga menjadi acuan bagi pemerintah Provinsi Maluku dalam menurunkan jumlah kematian bayi.

Tujuan yang ingin dicapai dalam penelitian ini adalah Memodelkan jumlah kematian bayi di Provinsi Maluku tahun 2010 berdasarkan faktor-faktor yang 
mempengaruhinya dengan menggunakan model regresi Poisson.

\section{TINJAUAN PUSTAKA}

Kematian bayi adalah kematian yang terjadi antara saat setelah bayi lahir sampai bayi belum berusia tepat satu tahun. Banyak faktor yang dikaitkan dengan kematian bayi. Secara garis besar, dari sisi penyebabnya, kematian bayi ada dua macam yaitu endogen dan eksogen. Kematian bayi endogen atau yang umum disebut dengan kematian neonatal adalah kematian bayi yang terjadi pada bulan pertama setelah dilahirkan, dan umumnya disebabkan oleh faktor-faktor yang dibawa anak sejak lahir, yang diperoleh dari orang tuanya pada saat konsepsi atau didapat selama kehamilan. Kematian bayi eksogen atau kematian post neonatal, adalah kematian bayi yang terjadi setelah usia satu bulan sampai menjelang usia satu tahun yang disebabkan oleh faktorfaktor yang bertalian dengan pengaruh lingkungan luar. Kematian bayi disebabkan oleh beberapa faktor yaitu : usia ibu pada saat melahirkan, jumlah pemeriksaan yang dilakukan oleh ibu pada saat hamil, tingkat pendidikan ibu, jumlah sarana kesehatan, persentase daerah yang berstatus desa, dan lain-lain.

Model regresi Poisson merupakan model standar untuk data diskrit dan termasuk dalam model regresi nonlinier. Regresi Poisson berdasarkan pada penggunaan distribusi Poisson.

Misalkan terdapat sekumpulan data dengan struktur sebagai berikut :

$$
\left[\begin{array}{ccccc}
Y_{1} & X_{11} & X_{21} & \cdots & X_{k 1} \\
Y_{2} & Y_{12} & Y_{22} & \cdots & Y_{k 2} \\
\vdots & \vdots & \vdots & & \vdots \\
Y_{n} & X_{1 n} & X_{2 n} & \cdots & X_{k n}
\end{array}\right]
$$

dengan $y_{i}$ adalah observasi ke- $i$ dari variabel respon $\mathrm{Y}$, dan $x_{j i}$ adalah nilai variabel predictor $X_{j}$ $(j=1,2, \ldots, k)$, maka model regresi Poisson dapat dinyatakan sebagai berikut:

$$
\mu_{i}=\mu\left(\mathbf{x}_{i}, \boldsymbol{\beta}\right)=\exp \left(\boldsymbol{x}_{i}^{T} \boldsymbol{\beta}\right) ; i=1,2, \ldots, n
$$

Variabel $\mu_{i}$ adalah rata-rata jumlah kejadian yang terjadi dalam interval waktu tertentu. Bila $\mu_{i}$ diasumsikan tidak berubah secara independen dari data ke data, maka $\mu_{i}$ dapat dimodelkan sebagai fungsi $\mathrm{k}$ variabel prediktor.

\section{Dengan}

$$
\mathbf{x}_{\mathrm{i}}^{\mathrm{T}}=\left[x_{1 i}, x_{2 i}, \ldots, x_{k i}\right] \text { dan } \boldsymbol{\beta}=\left[\beta_{1}, \beta_{2}, \ldots, \beta_{k}\right]^{T}
$$

Penaksiran parameter regresi Poisson dilakukan dengan menggunakan metode Maximum Likelihood
Estimation (MLE). Taksiran maksimum likelihood untuk parameter $\boldsymbol{\beta}$ dinyatakan dengan $\hat{\boldsymbol{\beta}}$ yang merupakan penyelesaian dari turunan pertama dari fungsi likelihoodnya, yaitu :

$$
\begin{aligned}
L(\boldsymbol{\beta}) & =\prod_{i=1}^{n} P\left(y_{i}, \boldsymbol{\beta}\right) \\
& =\prod_{i=1}^{n} \frac{\left[\mu\left(\mathbf{x}_{i}, \boldsymbol{\beta}\right)\right]^{y_{i}} \exp \left(-\mu\left(\mathbf{x}_{i}, \boldsymbol{\beta}\right)\right)}{y_{i} !} \\
& =\frac{\left\{\prod_{i=1}^{n}\left[\mu\left(\mathbf{x}_{i}, \boldsymbol{\beta}\right)\right]^{y_{i}}\right\} \exp \left(-\sum_{i=1}^{n} \mu\left(\mathbf{x}_{i}, \boldsymbol{\beta}\right)\right)}{\prod_{i=1}^{n} y_{i} !}
\end{aligned}
$$

Fungsi log natural-likelihoodnya adalah :

$$
\ln L(\boldsymbol{\beta})=\sum_{i=1}^{n} y_{i} \ln \left[\mu\left(\mathbf{x}_{i}, \boldsymbol{\beta}\right)\right]-\sum_{i=1}^{n} \mu\left(\mathbf{x}_{i}, \boldsymbol{\beta}\right)-\sum_{i=1}^{n} \ln \left(y_{i} !\right)
$$

Kemudian persamaan (2) diturunkan terhadap $\beta$ disamakan dengan nol sebagai syarat perlu $\frac{\partial \ln L(\beta)}{\partial \beta}=0$ Pada beberapa kasus tertentu, cara derivatif ini kadang tidak menghasilkan suatu solusi yang eksplisit karena persamaanya masih berbentuk implisit. Untuk mendapatkan taksiran maksimum likelihood untuk parameter $\boldsymbol{\beta}$ maka digunakan metode iterasi numerik yaitu Newton-Raphson. Ide dasar dari model ini adalah memaksimumkan fungsi likelihood (Myers, 1990). Algoritma untuk optimisasi dengan metode NewtonRaphson dapat dituliskan sebagai berikut :

1. Menetukan nilai taksiran awal parameter $\hat{\beta}_{(0)}$. Penentuan nilai awal ini biasanya diperoleh dengan metode Ordinary Least Square (OLS), yaitu :

$$
\hat{\beta}_{(0)}=\left(X^{\prime} X\right)^{-1} X^{\prime} Y
$$

$$
X=\left[\begin{array}{cccc}
1 & x_{1,1} & \cdots & x_{k, 1} \\
1 & x_{1,2} & \cdots & x_{k, 2} \\
\vdots & \vdots & & \vdots \\
1 & x_{1, n} & \cdots & x_{k, n}
\end{array}\right] \quad y=\left[\begin{array}{llll}
y_{1} & y_{2} & \cdots & y_{n}
\end{array}\right]^{T}
$$

2. Membentuk vektor gradien $g$.

$$
g^{T}\left(\beta_{(m)}\right)_{(k+1) x_{1}}=\left(\frac{\partial \ln L(\beta)}{\partial \beta_{0}}, \frac{\partial \ln L(\beta)}{\partial \beta_{1}}, \cdots, \frac{\partial \ln L(\beta)}{\partial \beta_{k}}\right)_{\beta=\beta_{(m)}}
$$

dengan $k$ adalah banyaknya parameter yang ditaksir.

3. Membentuk matriks Hessian $\mathbf{H}$.

Matriks Hessian ini disebut juga matriks informasi. 


$$
H\left(\beta_{(m)}\right)_{(k+1) x(k+1)}=\left(\begin{array}{cccc}
\frac{\partial^{2} \ln L(\beta)}{\partial \beta_{0}{ }^{2}} & \frac{\partial^{2} \ln L(\beta)}{\partial \beta_{0} \beta_{1}} & \cdots & \frac{\partial^{2} \ln L(\beta)}{\partial \beta_{0} \beta_{k}} \\
& \frac{\partial^{2} \ln L(\beta)}{\partial \beta_{1}^{2}} & \cdots & \frac{\partial^{2} \ln L(\beta)}{\partial \beta_{1} \beta_{k}} \\
& \ddots & \vdots \\
& & \frac{\partial^{2} \ln L(\beta)}{\partial \beta_{k}^{2}}
\end{array}\right)_{\beta=\beta_{(m)}}
$$

4. Memasukkan nilai $\hat{\beta}_{(0)}$ ke dalam elemen-elemen vektor $g$ dan matriks $\mathbf{H}$, sehingga diproleh vektor $g\left(\hat{\beta}_{(0)}\right)$ dan matriks $H\left(\hat{\beta}_{(0)}\right)$.

5. Mulai dari $m=0$ dilakukan iterasi pada persamaan :

$$
\hat{\beta}_{(m+1)}=\hat{\beta}_{(m)}-H^{-1}(m) g_{(m)}
$$

Nilai $\hat{\beta}_{(m)}$ merupakan sekumpulan penaksir parameter yang konvergen pada iterasi ke-m. Jika belum didapatkan penaksir parameter yang konvergen, maka dilanjutkan kembali langkah 5 hingga ietrasi ke $m=m+1$. Iterasi berhenti pada keadaan konvergen yaitu pada saat $\left\|\beta_{(m+1)}-\beta_{(m)}\right\| \leq \varepsilon$, dimana $\varepsilon$ merupakan bilangan yang sangat kecil sekali.

Untuk menguji kelayakan model regresi poisson, terlebih dahulu ditentukan dua buah fungsi likelihood yang berhubungan dengan model regresi yang diperoleh. Fungsi-fungsi likelihood yang dimaksud adalah $L(\hat{\Omega})$ yaitu nilai maksimum likelihood untuk model yang lebih lengkap dengan melibatkan variabel bebas dan $L(\hat{\omega})$, yaitu nilai maksimum likelihood untuk model sederhana tanpa melibatkan variabel bebas. Salah satu metode yang dapat digunakan untuk menentukan statistik uji dalam pengujian parameter model regresi Poisson adalah dengan menggunakan metode Maximum Likelihood Ratio Test (MLRT). Likelihood ratio dinotasikan dengan :

$$
\Lambda=\frac{L(\widehat{\omega})}{L(\widehat{\Omega})}
$$

Regresi Poisson termasuk dalam keluarga exponensial sehingga likelihood ratio pada persamaan (5) dapat juga ditulis dalam bentuk (Hardin dan Hilbe, 2007) :

$$
-2 \ln \Lambda
$$

Atau dapat ditulis sebagai berikut :

$$
D(\widehat{\boldsymbol{\beta}})=-2 \ln \Lambda=-2 \ln \left(\frac{L(\widehat{w})}{L(\widehat{\Omega})}\right)=2(\ln (\widehat{\Omega})-\ln (\widehat{w}))
$$

$D(\hat{\beta})$ merupakan devians model regresi Poisson atau devians yang dihitung pada seluruh parameter dalam model. Nilai $D(\hat{\beta})$ yang semakin kecil menyebabkan semakin kecil pula tingkat kesalahan yang dihasilkan oleh model, sehingga medel menjadi semakin tepat. $D(\hat{\beta})$ disebut juga sebagai statistik rasio likelihood, dimana untuk ukuran sampel besar distribusi dari statistik uji pada persamaan (7) akan mengikuti distribusi khi-kuadrat dengan derajat bebasnya adalah banyaknya parameter model dibawah populasi dikurangi dengan banyaknya parameter dibawah $H_{0}$.

Pengujian kelayakan model yang diperoleh dari estimasi parameter dilakukan dengan menggunakan metode Maximum Likelihood Ratio Test (MLRT) dengan melakukan pengujian hipotesis-hipotesis berikut:

$$
\begin{aligned}
& \mathrm{H}_{0}: \beta_{1}=\beta_{2}=\ldots=\beta_{k}=0 . \\
& \mathrm{H}_{1}: \text { Paling sedikit ada satu } \beta_{j} \neq 0 .
\end{aligned}
$$

Kriteria pengujiannya adalah tolak $H_{0}$ jika $D(\hat{\beta})>\chi_{(\alpha ; n-k-1)}^{2}$ Menurut McCullagh dan Nelder (1989) harga devians ini akan berkurang seiring dengan bertambahnya parameter ke dalam model.

Selanjutnya dilakukan pengujian parameter model secara parsial yaitu untuk mengetahui parameter mana yang memberikan pengaruh signifikan terhadap model. Misalkan, ingin menguji apakah parameter $\beta_{j}$ berpengaruh terhadap model, dan dapat dirumuskan sebagai berikut :

$$
\begin{aligned}
& H_{0}: \beta_{j}=0 \\
& H_{1}: \beta_{j} \neq 0 \quad ; j=1,2, \ldots, k
\end{aligned}
$$

Dalam pengujian hipotesis di atas dapat digunakan statistik uji sebagai berikut :

$$
t=\frac{\widehat{\beta}_{j}}{S E\left(\widehat{\beta}_{j}\right)}
$$

Kriteria pengujiannya adalah tolak $H_{0}$ jika $\left|t_{\text {hit }}\right|>$ $t_{(\alpha / 2 ; n-(k+1))}$

Multikolinieritas adalah adanya hubungan antara variabel bebas yang satu dengan variabel bebas yang lain. Untuk mendeteksi adanya multikolinieritas juga dapat menggunakan Variance Inflation Factors (VIF) yang dinyatakan sebagai berikut :

$$
V I F_{j}=\frac{1}{1-R_{j}^{2}}
$$

Dengan $R_{j}^{2}$ adalah koefisien determinasi antara $\mathrm{X}_{\mathrm{j}}$ dengan variabel prediktor lainnya. $V I F_{j}$ yang lebih besar dari 10 menunjukan adanya kolinieritas antar variabel prediktor. Solusi untuk mengatasi adanya kasus tersebut adalah dengan mengeluarkan variabel prediktor yang tidak signifikan dan meregresikan kembali variabelvariabel prediktor yang signifikan.

\section{HASIL DAN PEMBAHASAN}

Pada penelitian ini aplikasi model Regresi Poisson diterapkan pada kasus kematian bayi di Provinsi Maluku pada tahun 2010. Variabel yang diteliti yaitu jumlah kematian bayi yang berusia di bawah satu tahun per seribu kelahiran hidup pada tahun 2010 sebagai variabel respon dan persentase persalinan yang dilakukan dengan bantuan non medis, persentase kunjungan ibu hamil ke puskesmas untuk imunisasi, rata-rata jumlah pengeluaran rumah tangga perkapita sebulan, rata-rata pemberian ASI ekslusif, persentase penduduk miskin, jumlah tenaga 
kesehatan (Dokter dan Bidan), jumlah sarana kesehatan (RS dan Puskesmas) sebagai variabel prediktornya. Berikut deskriptif dari masing-masing variabel untuk Provinsi Maluku.

Tabel 1 Deskriptif Data Kematian Bayi di Maluku

\begin{tabular}{|c|c|c|c|c|c|}
\hline Variabel & $\mathbf{N}$ & Mean & Minimum & Maximum & Standar Deviasi \\
\hline$Y$ & 11 & 6.3636 & 1.00 & 11.00 & 2.94186 \\
\hline$X_{1}$ & 11 & 59.6255 & 26.94 & 85.54 & 19.26293 \\
\hline$X_{2}$ & 11 & 59.0127 & 34.79 & 76.18 & 15.86346 \\
\hline$X_{3}$ & 11 & 401.5675 & 325.28 & 692.18 & 103.09420 \\
\hline$X_{4}$ & 11 & 8.6136 & 5.16 & 11.59 & 1.73646 \\
\hline$X_{5}$ & 11 & 28.6609 & 7.67 & 39.28 & 8.41580 \\
\hline$X_{6}$ & 11 & 245.1818 & 101.00 & 610.00 & 170.61994 \\
\hline$X_{7}$ & 11 & 63.4545 & 26.00 & 125.00 & 27.11591 \\
\hline
\end{tabular}

Tabel 1 menunjukkan bahwa rata-rata jumlah kematian bayi di Provinsi Maluku pada tahun 2010 adalah 6 orang per seribu kelahiran hidup dimana jumlah kematian bayi terendah berada pada Kabupaten Maluku Barat Daya sedangkan jumlah kematian bayi tertinggi berada pada Kabupaten Maluku Tengah dengan 11 orang per seribu kelahiran. Rata-rata persentase persalinan yang dilakukan dengan bantuan non medis di Provinsi Maluku pada tahun 2010 adalah 59,6255\%, dimana Kota Ambon memiliki persentase persalinan yang dilakukan dengan bantuan non medis terendah dan Kabupaten Seram Bagian Timur tertinggi. Rata-rata pemberian ASI ekslusif di Provinsi Maluku pada tahun 2010 berkisar antara 5,16 sampai dengan 11,59 dimana pemberian ASI ekslusif tertinggi berada pada Kota Tual dan pemberian ASI ekslusif terendah berada pada Kota Ambon.

Sebelum menganalisis Regresi Poisson, perlu dilakukan uji kolinieritas. Uji ini bertujuan untuk mengetahui apakah variabel-variabel predictor telah memenuhi kondisi saling tidak berkorelasi. Kriteria yang digunakan untuk memeriksa kolinieritas antar variabelvariabel prediktor adalah dengan menggunakan nilai Variance Inflation Factors (VIF) pada variabel-variabel prediktor. Berikut ini adalah nilai VIF untuk masingmasing variabel prediktor di Provinsi Maluku tahun 2010

Tabel 2 Nilai VIF Variabel Prediktor di Provinsi Maluku

\begin{tabular}{|c|c|c|c|c|c|c|}
\hline \multicolumn{7}{|c|}{ Nilai VIF } \\
\hline $\boldsymbol{X}_{\boldsymbol{1}}$ & $\boldsymbol{X}_{\mathbf{2}}$ & $\boldsymbol{X}_{\mathbf{3}}$ & $\boldsymbol{X}_{\mathbf{4}}$ & $\boldsymbol{X}_{5}$ & $\boldsymbol{X}_{\mathbf{6}}$ & $\boldsymbol{X}_{7}$ \\
\hline 3,557 & 2,251 & 7,363 & 2,737 & 4,829 & 9,958 & 4,162 \\
\hline
\end{tabular}

Nilai VIF masing-masing variabel prediktor pada Tabel 2 menunjukkan nilai kurang dari 10, maka antar variabel prediktor di Provinsi Maluku dapat dikatakan tidak saling berkorelasi. Sehingga variabel-variabel prediktor di Provinsi Maluku tahun 2010 dapat digunakan dalam pembentukkan model Regresi Poisson. Selanjutnya dilakukan estimasi parameter model Regresi Poisson. Berdasarkan software SAS 9.0 diperoleh hasil sebagai berikut:
Tabel 3 Estimasi Parameter Model Regresi Poisson di Provinsi Maluku

\begin{tabular}{|c|c|c|c|c|c|c|c|}
\hline Parameter & Estimasi & SE & DF & t & P-Value & Lower & Uper \\
\hline$\beta_{0}$ & 1,6940 & 0,9441 & 11 & 1,79 & 0,1003 & $-0,3840$ & 3,7719 \\
\hline$\beta_{1}$ & 0,08017 & 0,02434 & 11 & 3,29 & 0,0072 & 0,02660 & 0,1337 \\
\hline$\beta_{2}$ & 0,007328 & 0,003396 & 11 & 2,16 & 0,0539 & $-0,00015$ & 0,01480 \\
\hline$\beta_{3}$ & 0,005287 & 0,003957 & 11 & 1,34 & 0,2085 & $-0,00342$ & 0,01400 \\
\hline$\beta_{4}$ & 0,000957 & 0,001157 & 11 & 0,83 & 0,4206 & $-0,00159$ & 0,00350 \\
\hline$\beta_{5}$ & 0,003444 & 0,03503 & 11 & 0,10 & 0,9234 & $-0,07365$ & 0,08054 \\
\hline$\beta_{6}$ & 0,01350 & 0,01245 & 11 & 1,08 & 0,3014 & $-0,01391$ & 0,04091 \\
\hline$\beta_{7}$ & 0,001364 & 0,000467 & 11 & 2,92 & 0,0139 & 0,000336 & 0,002393 \\
\hline
\end{tabular}

Berdasarkan Tabel 3 didapatkan nilai $t_{\text {hit }}$ dan $P$ Value untuk semua parameter. Dengan menggunakan tingkat signifikansi $(\alpha)$ sebesar $5 \%$ maka nilai $t_{(0,025 ; 3)}=$ 2,18 . Maka diperoleh 2 parameter yang signifikan yaitu $\beta_{1}$ dan $\beta_{7}$ karena $\left|t_{\text {hit }}\right|>\left|t_{\text {tabel }}\right|$ atau P-Value $<\alpha$, sehingga model regresi Poisson yang dibentuk untuk kematian bayi di Provinsi Maluku adalah :

$$
\mu=\exp \left(0,08017 X_{1}+0,001364 X_{7}\right)
$$

Model di atas menjelaskan bahwa jumlah kematian bayi di Provinsi Maluku tahun 2010 akan bertambah sebesar $\exp (0,081017)$ jika variabel $X_{1}$ bertambah sebesar satu satuan dengan syarat variabel prediktor yang lain adalah konstan. Kemudian jumlah kematian bayi di Provinsi Maluku tahun 2010 akan bertambah sebesar $\exp (0,001364)$ jika variabel $X_{7}$ bertambah sebesar satu satuan dengan syarat variabel prediktor yang lain adalah konstan.

Untuk menguji kelayakan model regresi Poisson, digunakan nilai devians $D(\hat{\beta})$ atau disebut juga sebagai statistik likelihood ratio, dimana statistik ini merupakan pendekatan dari distribusi $\chi^{2}$ dengan derajat bebas $n-k-1$ di bawah model yang sedang diamati adalah benar. Kriteria pengujiannya adalah tolak $H_{0}$ apabila $D(\hat{\beta})>\chi_{(\alpha ; n-k-1)}^{2}$. Hipotesis yang digunakan yaitu:

$H_{0}: \beta_{1}=\beta_{2}=\cdots=\beta_{k}=0$ (model tidak sesuai)

$H_{1}$ : paling sedikit ada satu $\beta_{k} \neq 0$ (model sesuai)

Dengan menggunakan software SAS 9.0 diperoleh hasil sebagai berikut:

Tabel 4 Analisis Kesesuaian Model Regresi Poisson

\begin{tabular}{|c|c|c|}
\hline Devians & db & $\chi_{(\mathbf{0 , 0 5} ; \mathbf{3})}^{2}$ \\
\hline 88,5 & 3 & 7,81472 \\
\hline
\end{tabular}

Berdasarkan Tabel 4 diperoleh nilai devians sebesar 88,5 . Dengan menggunakan tingkat signifikansi $(\alpha)$ sebesar $5 \%$ yang menghasilkan $\chi_{(0,05 ; 3)}^{2}$ sebesar 7,81472 maka keputusan yang dihasilkan adalah terima $H_{0}$ karena nilai $D(\hat{\beta})>\chi_{(0,05 ; 3)}^{2}$. Sehingga model regresi Poisson layak dan sesuai untuk menggambarkan hubungan antara variabel respon dan variabel prediktor. 


\section{KESIMPULAN}

Dari hasil analisa data dan pembahasan dapat diperoleh kesimpulan sebagai berikut :

1. Berdasarkan jumlah kematian bayi beserta faktorfaktor yang mempengaruhinya, diperoleh bahwa :

a. Rata-rata jumlah kematian bayi di Provinsi Maluku pada tahun 2010 adalah 6 orang per seribu kelahiran hidup.

b. Rata-rata persentase persalinan yang dilakukan dengan bantuan non medis di Provinsi Maluku pada tahun 2010 adalah 59,63\%.

c. Rata-rata pemberian ASI ekslusif di Provinsi Maluku pada tahun 2010 berkisar antara 5,16 sampai dengan 11,59 bulan.

2. Berdasarkan model regresi Poisson diperoleh faktor-faktor yang signifikan mempengaruhi kematian bayi yaitu persentase persalinan yang dilakukan dengan bantuan non medis $\left(X_{1}\right)$ dan jumlah sarana kesehatan (RS dan Puskesmas) $\left(X_{7}\right)$. Sehingga model regresi Poisson adalah sebagai berikut :

$$
\mu=\exp \left(0,081017 X_{1}+0,001364 X_{7}\right)
$$

\section{DAFTAR PUSTAKA}

Walpole, R.E. (1982), Pengantar Statistika, edisi ketiga, Gramedia Pustaka Tama, Jakarta.

Myers, R.H. (1990), Classical and Modern Regression With Applications, PWS Kent Publishing Company, USA.

Setyorini, E. (2006), Pemodelan Regresi Poisson Pada Maternal Mortality di Jawa Timur. Tugas Akhir Jurusan Statistika FMIPA ITS, Surabaya.

Badan Pusat Statistik (2010), Angka Kematian Bayi, Data Statistik Indonesia.

Badan Pusat Statistik (2010), Maluku Dalam Angka, Badan Pusat Statistik Provinsi Maluku.

Aulele, S.N. \& Purhadi. (2010), Model Geographically Weighted Poisson Regression (Studi Kasus : Jumlah Kematian Bayi di Provinsi Jawa Timur \& Jawa Tengah Tahun 2007). Tesis Jurusan Statistika FMIPA ITS, Surabaya. 